\title{
DIÁLOGO ENTRE COMUNICAÇÃO E DIVULGAÇÂO CIENTÍFICA: REFLEXÕES PARA O DESENVOLVIMENTO DE HABILIDADES EM COMPETÊNCIA CRÍTICA DA INFORMAÇÃO
}

\author{
Fernanda Vasconcelos Amaral \\ Mestranda em Gestão da Informação pela Universidade \\ do Estado de Santa Catarina (UDESC). Bibliotecária na \\ Universidade Federal de Lavras (UFLA). \\ fernandav.br@gmail.com \\ https://orcid.org/0000-0001-6197-9548
}

\author{
Jordan Paulesky Juliani \\ Doutor em Engenharia e Gestão do Conhecimento pela \\ Universidade Federal de Santa Catarina (UFSC). \\ Professor no Departamento de Educação Científica e \\ Tecnológica da Universidade do Estado de \\ Santa Catarina (UDESC). \\ jordan@webpack.com.br \\ https://orcid.org/0000-0001-7823-6644
}

\section{RESUMO}

O presente artigo objetiva investigar as interações entre a comunicação e a divulgação científica e refletir sobre o modo como a ciência pode ser melhor compreendida e assimilada pelo público leigo. Trata-se de uma pesquisa bibliográfica, baseada em artigos de periódicos científicos, livros e jornalismo científico, sobre comunicação científica, divulgação científica, contexto informacional contemporâneo e competência crítica da informação. Conclui-se que o desenvolvimento de competência crítica da informação é uma habilidade essencial para aperfeiçoar o diálogo entre comunidade cientifica, os mediadores da informação científica e o público em geral.

Palavras-chave: Comunicação científica. Divulgação científica. Desinformação. Competência crítica da informação.

\section{DIALOGUE BETWEEN COMMUNICATION AND SCIENTIFIC DISSEMINATION: REFLECTIONS FOR SKILLS DEVELOPMENTIN CRITICAL COMPETENCE OF INFORMATION}

\begin{abstract}
This article aims to investigate the interactions between scientific communication and dissemination and reflect on how science can be better understood and assimilated by the lay public. This study is a bibliographic research based on articles from scientific journals, books and scientific journalism about the topics scientific communication, scientific dissemination, contemporary information context and critical competence of information. It is concluded that the development of critical information competence is an essential skill to enhance the dialogue between scientific communities, mediators of scientific information and the public in general.
\end{abstract}

Keywords: Scientific communication.Scientific dissemination.Disinformation. Criticalinformationcompetence

Aceito em:30/07/2020

Publicado em: 11/09/2020

\section{INTRODUÇÃO}

No desenvolvimento da ciência e difusão dos conhecimentos gerados estão inseridos dois processos distintos: a comunicação científica e a divulgação científica. Esses processos possuem características particulares, com um fluxo de informação bastante diferenciado, mas que necessitam estabelecer uma interação eficiente para que a informação científica seja capaz de beneficiar a sociedade e seus cidadãos. 
No contexto contemporâneo, marcado pelo advento da desinformação, os fatos científicos são, muitas vezes, rechaçados ou mal interpretados. Em parte, essa situação ocorre devido à falta de compreensão do público leigo sobre o modo como o conhecimento científico é construído. Por isso, aperfeiçoar o diálogo entre os processos de comunicação e divulgação cientifica é essencial para auxiliar na formação de cidadãos críticos e bem informados e recuperar a credibilidade e a confiança nos fatos científicos.

Dessa forma, este artigo se propõe a refletir sobre a necessidade de tornar o processo de comunicação científica compreensível pelo público leigo, de forma a torná-lo crítico em relação às informações científicas divulgadas. Por meio dessa compreensão, espera-se uma diminuição dos ruídos de comunicação entre cientistas e o público em geral, contribuindo para potencializar o papel da ciência, na sociedade.

O procedimento metodológico adotado,para essa reflexão, é a revisão de literatura de periódicos e livros científicos, em conjunto com a busca de informações em canais de jornalismo científico. Essa pesquisa caracteriza-se como descritiva, pois pretende: a) discorrer sobre os conceitos e características dos processos de comunicação e divulgação cientifica; b) abordar o contexto informacional contemporâneo; c) apresentar o conceito de competência crítica, em informação, e discutir seu papel para intermediar a interação entre a construção do saber científico (comunicação científica) e sua difusão e assimilação pelo público leigo. (divulgação científica).

\section{COMUNICAÇÃO E DIVULGAÇÃO CIENTÍFICA}

A comunicação cientifica é definida por Garvey (1979) como

o conjunto de atividades associadas à produção, disseminação e uso da informação, desde o momento em que o cientista concebe uma ideia para pesquisar, até que a informação acerca dos resultados seja aceita como constituinte do conhecimento científico. (apud MIRANDA; PEREIRA, 1996, p. 375)

O processo da comunicação científica, portanto, abrange desde a geração da informação, por meio do desenvolvimento de uma pesquisa, até a validação dos resultados por outros membros da comunidade científica. O assim chamado "sistema de revisão por pares" (peer review system) visa detectar trabalhos originais, com metodologias e análises de resultados consistentes, além de apontar erros, omissões, 
desvios de ética ou conflitos de interesse, no desenvolvimento da pesquisa. (COIMBRA JUNIOR, 2003).

A Figura 1 estrutura as principais etapas do processo de comunicação científica e as fontes de informação, que são geradas em cada etapa. O diagrama demonstra que as primeiras obras a surgirem são as que formam a literatura cinzenta: relatórios, prepints e publicações geradas em eventos. A sequência normal é a publicação de artigos e, posteriormente, os conteúdos aparecem em textos didáticos, atingindo a área da literatura comercial. Ao longo desse processo, o texto é citado por outros autores, e surgem as fontes de informações secundárias e terciárias.

FIGURA 1 - Modelo tradicional da comunicação científica

MODELO TRADICIONAL DA COMUNICAÇĀO

CIENTIFICA DE GARVEY E GRIFFITH (ADAPTADO)

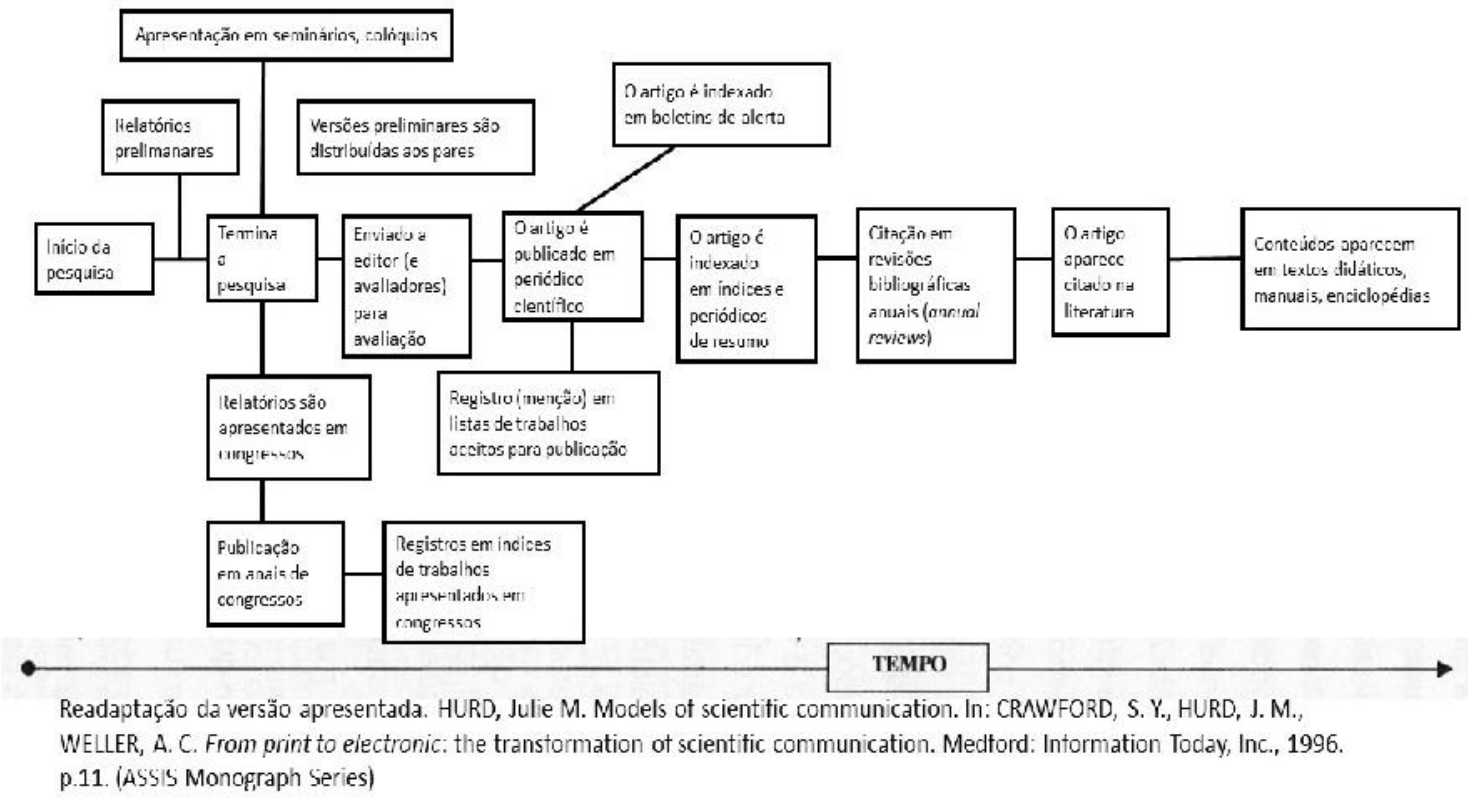

Fonte: Adaptado por Mueller.(2000).

O periódico científico constitui-se na mais proeminente fonte de informação, dentro da comunicação científica. Há várias métricas de avaliação para ordenar o nível de qualidade dessas publicações. No Brasil, a métrica mais importante é o sistema Qualis, mantido pela Coordenação de Aperfeiçoamento de Pessoal de Nível Superior (Capes), que classifica os periódicos em 8 estratos: A1, A2, B1, B2, B3, B4, B5 e C. (FRIGERl; MONTEIRO, 2014). Os periódicos $A 1$ possuem a classificação mais elevada e constituem-se em publicações de grande excelência. Por sua vez, os periódicos 
do extrato $C$ englobam publicações de baixa relevância no cenário científico. A Capes lista, também, os chamados periódicos predatórios, assim denominados por serem publicações com critérios inadequados, ou mesmo fraudulentos, para selecionar artigos a uma publicação, sendo, por isso, abominados pela comunidade científica.

A comunicação científica, portanto, abrange um complexo fluxo de informação, que visa garantir a confiabilidade da informação gerada nas pesquisas cientificas. Para obter essa credibilidade, a informação científica apoia-se em duas características fundamentais: 1) a adoção de uma metodologia rigorosa, para obtenção de dados e geração de conhecimentos (método científico); 2) a submissão dos resultados a uma avaliação e julgamento criteriosos por parte de outros cientistas (avaliação por pares). (MUELLER, 2000).

A divulgação científica, por sua vez, é o processo de "veiculação de informações científicas, tecnológicas ou associadas a inovações ao público leigo". (BUENO, 2009, p. 162). Neste contexto, pressupõe-se que haverá uma "tradução" da linguagem especializada da comunicação científica para uma linguagem acessível a um público mais amplo. (ALBAGLI, 1996).

Os canais para divulgação científica são bastante diversos e abrangem os meios de comunicação em massa (rede de televisão, estações de rádio, jornais e revistas), livros didáticos, palestras e eventos de ciências, museus e centros de ciências, folhetos da área de saúde, campanhas publicitárias ou de educação, entre diversas outras fontes. (ALBAGLI, 1996; BUENO, 2009).

Uma área particularmente importante, nesse processo de divulgação, é o jornalismo científico, que, tal como os periódicos da comunicação científica, possuem diferentes níveis de qualidade e de aprofundamento da informação. Há veículos informativos mais gerais, tais como portais de informações ou jornais televisivos. Mas há, também,fontes mais especializadas, como as revistas Superinteressante, Galileu ou documentários da National Geographic, que contam com especialistas formados para mediar a informação cientifica a um público sem formação técnico-científica.

Bueno (2010) estabelece quatro aspectos, que distinguem a comunicação da divulgação científica. Primeiramente, a comunicação é centrada no público, os especialistas e cientistas, enquanto a divulgação foca em um público amplo não-especializado. O nível do discurso também é diferenciado, pois a comunicação científica é caracterizada pela utilização de um jargão técnico-cientifico, que terá de ser codificado para uma linguagem 
popular, ao realizar a divulgação científica. Outro ponto divergente é a natureza dos canais utilizados nos dois processos. A comunicação cientifica utiliza veículos de comunicação restritos e especializados, preocupados com o rigor científico. Já a divulgação científica, utiliza veículos de comunicação de amplo acesso às massas e, muitas vezes, preocupa-se mais em espetacularizar a notícia para atrair mais audiência a atentar-se com a completude e precisão da informação. Por fim, a intenção de cada um desses processos é, particularmente, distinta:

A comunicação científica visa, basicamente, à disseminação de informações especializadas entre os pares, com o intuito de tornar conhecidos, na comunidade científica, os avanços obtidos (resultados de pesquisas, relatos de experiências, etc.) em áreas específicas ou à elaboração de novas teorias ou refinamento das existentes. A divulgação científica cumpre função primordial: democratizar 0 acesso ao conhecimento científico e estabelecer condições para a chamada alfabetização científica. Contribui, portanto, para incluir os cidadãos no debate sobre temas especializados e que podem impactar sua vida e seu trabalho, a exemplo de transgênicos, células tronco, mudanças climáticas, energias renováveis e outros itens. (BUENO, 2010, p. 5)

Apesar das divergências, a comunicação e a divulgação científicas são processos que fazem parte do desenvolvimento da ciência e das sociedades. É o fluxo de informação advindo da comunicação científica, que abastece os investigadores para que continuem suas pesquisas, enquanto a divulgação científica possui o importante papel de popularizar os resultados alcançados em suas análises.

\section{CONTEXTO INFORMACIONAL CONTEMPORÂNEO}

As instituições religiosas já foram as grandes detentoras de autoridade para explicar o surgimento e o funcionamento do mundo. Fenômenos como terremotos ou tempestades que arrasavam plantações e levavam a períodos de escassez de comida já foram, há não tanto tempo, explicados como fruto da ira divina.

Com o desenvolvimento da ciência,houve uma ruptura do poder religioso e os cientistas ocuparam o posto dos sacerdotes, no que se refere ao papel de explicar os fenômenos que ocorrem no mundo. Não só eventos naturais, como fenômenos sociais também.

$\mathrm{Na}$ esteira do desenvolvimento científico, surgiram a imprensa e, posteriormente, os meios de comunicação em massa. Esses veículos são importantes fontes 
de disseminação de informações, além de desempenhar um papel de influenciar as pessoas, por meio das informações que escolhem divulgar.

Essas três instituições: Igreja, Ciência e Imprensa, apesar de serem formadas por membros distintos da sociedade e exercerem diferentes papéis na sociedade, tiveram, por muito tempo, dois aspectos em comum. Primeiramente, o poder da influência, pois foram, e ainda são, capazes de induzir as massas a acreditarem nas informações disseminadas por essas entidades. Segundo, pois suas comunidades exerceram um monopólio sobre a informação e o conhecimento, constituindo, cada uma a sua maneira, um grupo restrito de pessoas, que excluía grande parte da população.

Porém, a capacidade de gerar e disseminar novas informações foi alterada apenas com a criação e expansão da internet. A partir de então, qualquer pessoa com acesso à rede mundial de computadores passou a ter voz e a ser capaz de divulgar suas próprias ideias e a influenciar outras pessoas.

Inicialmente, a internet, com seus blogs e mídias sociais, prometia ser uma tecnologia que propiciava a liberdade de expressão e disseminação de ideias, de uma forma mais democrática e acessível para todos. Ao invés de concentrar o poder de transmissão de ideias nas mãos de poucos grupos de comunicação, todos os usuários da rede online teriam, teoricamente, a capacidade de se tornarem produtores de conteúdo. Em uma certa medida, esse objetivo foi alcançado e as mídias tradicionais perderam grande parte de sua influência e grupos, antes ignorados, adquiriram voz.

A partir dos anos 2000, inicia o fenômeno dos criadores de conteúdo digital e dos influenciadores digitais. (KARHAWI, 2017). Nesse cenário, inúmeras pessoas, desde desconhecidos a celebridades, foram alçadas ao posto de formadores de opinião, inclusive na propagação de informações cientificas, ao tratar de assuntos como, por exemplo, meio ambiente e saúde. Apesar da sua importância para descentralizar o poder sobre a informação e permitir que uma diversidade de vozes e ideias inundassem a sociedade. Esse movimento fez com que vários indivíduos se tornassem subautoridades em assuntos sobre os quais não possuem nenhuma expertise.

Dessa forma, após a fase de euforia com as possibilidades aventadas pela internet, surge um ambiente de extrema desconfiança com as fontes de informação disponíveis e um questionamento sobre a qualidade e veracidade das informações disseminadas. Embora as mídias tradicionais também sejam, em geral, objeto de desconfiança 
devido a possíveis interesses ocultos ao divulgar uma informação, antes da internet, não havia um hábito tão arraigado de questionar as fontes produtoras de informações.

Ao mesmo tempo que existe essa suspeita com as fontes de informação, surge também, em paralelo, o hábito de "encaminhar" links de notícias para conhecidos por meio de aplicativos ou repostar esses links nos perfis sociais sem checar a veracidade da informação. Essa disseminação inconsequente de informações por meio das mídias sociais e aplicativos de conversa fazem com que falsos fatos sejam amplamente divulgados e alcance um amplo público em questão de horas ou dias.

Consequentemente, a sociedade da informação e do conhecimento transformou-se na sociedade da desinformação, com vários fatos sendo mal informados para o público, seja inadvertidamente ou por escolha do difusor da informação. A multiplicação das fontes de informações também contribui para gerar uma sobrecarga de informação, dificultando encontrar dados confiáveis em meio a tantas opções. Em meio a esse cenário caótico, a sociedade percebe-se muitas vezes perdida sobre a melhor maneira de se manter informada, em especial em relação às informações científicas, que são, muitas vezes, complexas, dificultando o rápido reconhecimento da divulgação de uma fake news e dados incompletos ou manipulados.

Em conjunto com o problema da disseminação de informação para as massas, no âmbito da epistemologia da ciência, o ideal de verdade objetiva é combalido por diferentes correntes epistemológicas e autores, tais como Karl Popper (Filósofo), Pierre Bourdier (Sociólogo) e Rafael Capurro (Cientista da Informação). O questionamento da objetividade na ciência, ou a falta dela, visa indagar sobre os limites do método científico e demonstrar que não há verdades absolutas, pois tudo depende do contexto e do recorte realizado durante as pesquisas.

Esses questionamentos epistemológicos são mais frequentes nas ciências humanas e sociais. Mas mesmo áreas consideradas como ciências duras tiveram que alterar seus paradigmas diante de certos problemas, como a física, por exemplo, que lida hoje com a física clássica, a física quântica e a teoria das cordas, para citar alguns conceitos.

Essas rupturas ou criação de novos paradigmas na ciência deram abertura para o ressurgimento de um certo "misticismo" explicativo, similar a época em que as instituições religiosas ainda eram enxergadas como o bastião do conhecimento. Florescem, então, ideias sobre o terraplanismo ou o criacionismo, em oposição à Teoria da Evolução 
de Darwin. Ainda mais perturbadores são o crescimento do movimento antivacina e o fato de terraplanistas terem sido homenageados por deputados brasileiros pela realização de seus "estudos". (NOGUEIRA, 2019).

Ademais, pesquisadores também começam a ser questionados por algumas ações pouco transparentes ou éticas, com a denúncia de pesquisas associadas as grandes empresas e à manipulação comercial. Para citar apenas dois exemplos, as empresas de tabaco e de açúcar, que produzem substâncias nocivas para a saúde das pessoas, retardaram, ao máximo, a divulgação de dados que prejudicassem seus produtos. (MEDIAVILLA, 2017). Por sua vez, a pesquisadora da Universidade de Nova York, Marion Nestle, em seu livro Food Politics, denuncia como, nos EUA, a indústria (e as pesquisas científicas) manipulam e fazem lobby para alterar a política alimentar no país, de acordo com interesses comerciais. (NESTLE, 2013).

$\mathrm{Na}$ área de ciências sociais, Bourdieu já afirmava que "a ideia de uma ciência neutra é uma ficção". (BOURDIEU, 1983, p. 148). Além disso, há, no campo científico, lutas concorrenciais entre grupos de pesquisadores ou departamentos/instituições, que estão em uma disputa permanente de poder, em relação aos aspectos ideológicos, epistemológicos, econômicos e políticos, envolvidos em uma pesquisa científica. (BOURDIEU, 1989).

Segundo Bourdieu (1983, p. 148), há uma "luta interna pela autoridade científica no campo das ciências sociais, isto é, o poder de produzir, impor e inculcar a representação legítima do mundo social" e

no domínio da pesquisa científica, os pesquisadores ou as pesquisa dominantes definem o que é, num dado momento do tempo, o conjunto de objetos importantes, isto é, o conjunto das questões que importam para os pesquisadores, sobre as quais eles vão concentrar seus esforços e, se assim posso dizer, "compensar", determinando uma concentração de esforços de pesquisa. (BOURDIEU, 2004, p. 24-25).

A ciência, dessa forma, não é desinteressada e não está imune às influências do ambiente onde está inserida. Contudo, na sociedade atual, esses questionamentos da imparcialidade/neutralidade/objetividade das ciências foram apropriados de tal forma pelo senso comum, que parece não ser possível encontrar mais do que semiverdades. Torna-se, então, necessário reestabelecer a confiança do cidadão de que as entidades cientificas, embora não sejam perfeitas, permanecem como as fontes de conhecimento mais fidedignas. 


\section{COMPETÊNCIA CRÍTICA EM INFORMAÇÃO}

Considerando os contextos apresentados nas seções anteriores, é patente a necessidade de adquirir a capacidade crítica para lidar com a enorme massa de informação(e desinformação), com a qual somos bombardeados, diariamente. Somente com o desenvolvimento da competência crítica em informação ( $\mathrm{CCl}$ ) será possível aprender a analisar, tanto a informação em si, quanto a fonte que veicula essa informação e o processo que fez com que essa chegasse ao grande público.

A CCl é definida como uma habilidade que

[...] prepara o usuário para olhar criticamente a informação e se capacitar para distinguir entre o que é relevante e/ou irrelevante, buscar fontes seguras de informação, hierarquizar as informações, utilizá-las, produzir novas informações, ser criativo, contextualizar etc. (BRISOLA; ROMEIRO, 2018 p. 75).

Portanto, o indivíduo com competência crítica em informação, mais do que possuir habilidades técnicas para lidar com fontes e sistemas de informação, deve possuir habilidades para realizar uma reflexão crítica das fontes acessadas e das informações recebidas.

Para isso, um conjunto de competências e atitudes são requeridas: 1) domínio instrumental de dispositivos informacionais (desenvolvimento de linguagem, habilidades de manusear sistemas, etc.); 2) capacidade de problematizar as necessidades informacionais, em termos conceituais e pragmáticos; 3) capacidade de análise da credibilidade da fonte emissora; 4) constante reavaliação dos critérios de atribuição de credibilidade de uma autoridade ou fonte; 5) uso ético da informação, considerando as necessidades de preservar ou descartar uma informação, replicá-la ou mantê-la em sigilo, 6) conhecimento das teorias sociais críticas e das teorias críticas da informação". (BRISOLA; SCHNEIDER; SILVA JÚNIOR, 2017).

A CCl constitui-se, dessa forma, em uma competência essencial a ser desenvolvida, tanto por profissionais que trabalham com divulgação científica, quanto pelo cidadão comum, que se depara, regularmente, com informações científicas, em contextos não especializados. Ou seja, profissionais e cidadãos necessitam entender como ocorre

\footnotetext{
${ }^{1}$ A CCl apoia-se principalmente na Teoria Crítica e Pedagogia Crítica, que advogam por uma atitude questionadora por parte do indivíduo frente às informações e educação formal e informal recebidas, visando formar um sujeito crítico, emancipado dos sistemas sociais e políticos que o oprime, e capaz de transformar a realidade na qual está inserida (BRISOLA; RAMOS JUNIOR, 2020).
} 
o processo de comunicação cientifica, suas etapas, suas fontes de informações e atores envolvidos, sejam eles pessoas físicas ou entidades institucionais.

Além disso, os profissionais que trabalham com informação científica e os cidadãos em geral devem assumir uma postura questionadora em relação aos dados apresentados e investigar o contexto no qual as pesquisas foram desenvolvidas. Precisam, ainda, adquirir possíveis interesses ocultos, tanto por parte das instituições de pesquisa, como das mídias e das instituições políticas que mediam a difusão da ciência.

Por meio do desenvolvimento dessa competência, os profissionais que trabalham com divulgação científica serão capazes compreender como ocorre o processo de criação de conhecimento na ciência, além de escolher fontes de comunicação cientifica confiáveis e fornecer uma informação mais apurada para o público do seu veículo de comunicação. O cidadão, por sua vez, será capaz de avaliar,com um maior senso crítico, notícias sobre fatos científicos e, até mesmo, decidir se aprofundar nas fontes primárias de informação científica, caso tenha interesse,além de perceber que os meios de divulgação cientificas possuem vieses que podem tornar as informações veiculadas pouco imparciais.

\subsection{O papel do bibliotecário na $\mathrm{CCl}$}

Nesse cenário, o bibliotecário deve auxiliar na promoção de programas de competência em informação que, além de ensinar instrumentos e estratégias de busca, destaque também a importância da escolha de boas fontes de informação e da avaliação da qualidade dessa informação encontrada. Esses programas podem ser implementados em escolas, universidades, redações de jornais e, até mesmo,ensinados a influenciadores digitais, interessados em produzir conteúdo confiável para seu público.

Percebe-se, portanto, um enfoque mais educativo e menos instrumental nas atribuições dos bibliotecários. O foco sai um pouco das questões relacionadas ao acesso à informação, que podem ser solucionadas mais facilmente com o auxílio de inúmeros recursos tecnológicos, e adquire um maior peso a problemática relacionada à questão da apropriação e do uso da informação 
Dessa forma, sugere-se que o bibliotecário auxilie na promoção da $\mathrm{CCl}$, no âmbito da alfabetização cientifica ${ }^{2}$, em parceria com outros profissionais da informação e educadores.Alguns temas a serem trabalhados nessas iniciavas são:

- História da ciência e da tecnologia: surgimento da ciência,benefícios trazidos pelas descobertas científicas (como diminuição da mortalidade infantil e aumento da expectativa de vida), relação da tecnologia com a sustentabilidade ambiental e social e reconhecimento do trabalho colaborativo, por trás de grandes descobertas das ciências e da tecnologia;

- Filosofia da ciência: noções básicas sobre método científico, desenvolvimento de paradigmas dentro do campo científico e ética de pesquisa;

- Fontes de informação científica:explicitar os critérios de classificação dos periódicos científicos pela Qualis/Capes; realizar uma curadoria de fontes de informação confiáveis, incluindo canais de TV educativos, canais no Youtube, perfis de cientistas nas mídias sociais, entre outros;

- Desinformação e fake news: diferença entre opinião e fato; como identificar notícias falsas; obscurantismo intelectual e ideologias;

- Jornalismo científico:diferenças entre o discurso jornalístico e o científico; ética do jornalista.

Esses temas poderiam ser trabalhados por meio de palestras, workshops, folhetos explicativos, canais do Youtube e mídias sociais da biblioteca ou da unidade/ambiente de informação, na qual o bibliotecário está inserido. Dessa forma, este profissional contribuirá na disseminação do conhecimento e na formação de cidadãos mais conscientes.

\section{CONSIDERAÇÕES FINAIS}

A comunicação e a divulgação na área da ciência são dois processos complementares, que necessitam de um melhor diálogo para que a informação científica alcance o cidadão. Esse alcance é necessário para que a população compreenda o valor gerado pelas ciências e seu potencial de modo a tornar a vida em sociedade melhor.

${ }^{2}$ De acordo com Miller (1983, tradução SASSERON; CARVALHO, 2011), o alfabetismo ou letramento científico apresenta três dimensões: a) entendimento da natureza da ciência; b) compreensão de termos e conceitos chave das ciências; c) entendimento dos impactos das ciências e suas tecnologias. 
Tanto o cidadão comum, quanto o profissional que media o acesso às informações científicas necessitam compreender como a ciência é desenvolvida, seus métodos e os paradigmas de cada área. Precisam entender, ainda, as fontes de informações mais qualificadas na comunicação e na divulgação cientifica; e principalmente, necessitam desenvolver uma atitude questionadora e crítica, no momento de acessar e disseminar a informação científica.

\section{REFERÊNCIAS}

ALBAGLI, S. Divulgação científica: informação científica para cidadania.Ciência da Informação, Brasília, v. 25, n. 3, p. 396-404, set./dez. 1996. Disponível em:

http://revista.ibict.br/ciinf/article/view/639/643. Acesso em: 10 abr. 2020.

BOURDIEU, P. O campo científico. In: ORTIZ, R. (Org). Pierre Bourdieu: sociologia. São Paulo: Ática, 1983. p. 122-155. (Grandes Cientistas Sociais, 39). Disponível em:

https://edisciplinas.usp.br/pluginfile.php/3001954/mod_resource/content/0/Renato\%200rtiz\%20\%2 8org.\%29.-A\%20sociologia\%20de\%20Pierre\%20Bourdieu.pdf. Acesso em: 06 abr. 2020.

BOURDIEU, P. O poder simbólico. Rio de Janeiro: Bertrand Brasil, 1989.

BOURDIEU, P. Os usos sociais da ciência: por uma sociologia clínica do campo científico. São Paulo: UNESP, 2004. Disponível em: https://cienciastecnologiassociedades.files.wordpress.com/2011/10/pierre_bourdieu_os_usos_sociais_da_cic3aancia.pdf. Acesso em: 06 abr. 2020.

BRISOLA, A. C. C.; RAMOS JUNIOR, M. A. C. O bibliotecário como um fator estratégico de marketing e de aprimoramento da competência crítica em informação. Revista Brasileira de Biblioteconomia e Documentação, São Paulo,v. 16, p. 1-21, 2020. Disponível em: https://rbbd.febab.org.br/rbbd/article/view/1324/1163. Acesso em: Acesso em: 14 abr. 2020. BRISOLA, A. C.; ROMEIRO, N. L. A competência crítica em informação como resistência: uma análise sobre o uso da informação na atualidade. Revista Brasileira de Biblioteconomia e Documentação, São Paulo, v. 14, n. 3, p. 68-87, set./dez. 2018. Disponível em: https://rbbd.febab.org.br/rbbd/ article/view/1054/1054. Acesso em: 03 fev. 2019.

BRISOLA, A. C.; SCHNEIDER, M.; SILVA JÚNIOR, M. J. F. Competência crítica em informação, ética intercultural da informação e cidadania global na era digital: fundamentos e complementaridades. In: ENCONTRO NACIONAL DE PESQUISA EM CIÊNCIA DA INFORMAÇÃO, 18., 2017, Marília. Anais eletrônicos... Marília: UNESP: 2017. Disponível em: http://enancib.marilia.unesp.br/index.php/xviiienancib/ENANCIB/paper/view/417. Acesso em: 10 abr. 2020.

BUENO, W. C. Comunicação cientifica e divulgação científica: aproximações e rupturas conceituais. Informação \& Informação, Londrina, v. 15, n. esp, p. 1-12, dez. 2010. Disponível em: http://www.uel.br/revistas/uel/index.php/informacao/article/view/6585. Acesso em: 10 abr. 2020.

BUENO, W. da C. B. Jornalismo cientifico: revisitando o conceito. In: VICTOR, C.; CALDAS, G.; BORTOLIERO, S. (Org.). Jornalismo científico e desenvolvimento sustentável. São Paulo: All Print, 2009. p. 157-78.

COIMBRA JUNIOR, C. E. A. Desafios à avaliação da literatura científica: a revisão pelos pares. Cadernos de Saúde Pública, Rio de Janeiro, v. 19, n. 5, p. 1224-1225, Out. 2003. Disponível em: http://www.scielo.br/pdf/csp/v19n5/17795.pdf. Acesso em: 10 abr. 2020. 
FRIGERI, M. MONTEIRO, M. S. A. Qualis Periódicos: indicador da política científica no Brasil? Revista Estudos de Sociologia, Araraquara, v. 19, n. 37, p. 299-315, jul.-dez. 2014. Disponível em: https://periodicos.fclar.unesp.br/estudos/article/view/6266/5227. Acesso em: 14 abr. 2020.

KARHAWI, I. Influenciadores digitais:conceitos e práticas em discussão. In: CONGRESSO BRASILEIRO CIENTÍFICO DE COMUNICAÇÃO ORGANIZACIONAL E RELAÇÕES PÚBLICAS, 11., 2017, Belo Horizonte. Anais eletrônicos... Porto Alegre: PUCRS, 2017. Disponível em: https://editora.pucrs.br/acessolivre/anais/abrapcorp/assets/edicoes/2017/arquivos/15.pdf. Acesso em: 06 abr. 2020.

MEDIAVILLA, D. A indústria do açúcar está há décadas manipulando a ciência. El País, [S.I.], 23 nov. 2017. Disponível em:

<https://brasil.elpais.com/brasil/2017/11/22/ciencia/1511374173_530869.html>. Acesso em: 06 abr. 2020.

MILLER, J. D. Scientific literacy: a conceptual and empirical review. Daedalus, [S.I.], v. 112, n. 2, p. 29-48, Spring 1983. Disponível em: https://www.jstor.org/stable/20024852?seq=1. Acesso em: 06 abr. 2020.

MIRANDA, D. B. de; PEREIRA, M. de N. F. O periódico científico como veículo de comunicação: uma revisão de literatura.Ciência da Informação, Brasília, v. 25, n. 3, set./dez. 1996. Disponível em: http://revista.ibict.br/ciinf/article/view/636/640. Acesso em: 14 abr. 2020.

MUELLER, S. P. M. A ciência, o sistema de comunicação científica e a literatura científica. In: CAMPELLO, B. S.; CENDÓN, B. V.; KREMER, J. M. (Org.). Fontes de informação para pesquisadores e profissionais. Belo Horizonte: UFMG, 2000. Cap. 1, p. 21-34.

NESTLE, M. Food politics: how the food industry influences nutrition and health. 10th ed. rev. exp. Berkeley: University of California, 2013. Disponível em:

https://books.google.com.br/books?hl=pt-

BR\&Ir=\&id=39oVBbtt6IEC\&oi=fnd\&pg=PP1\&dq=Marion+Nestle\&ots=2Y-

Nf3YDOD\&sig=FWIYSIxeVQ_FdlvL_NHp_Wyq3bU\#v=onepage\&q=Marion\%20Nestle\&f=false. Acesso em: 06 abr. 2020.

NOGUEIRA, S. O obscurantismo do século 21. Superinteressante, [S.I.], 3 jan. 2019. Disponível em: https://super.abril.com.br/opiniao/o-obscurantismo-do-seculo-21/. Acesso em: 06 abr. 2020.

SASSERON, L. H.; CARVALHO, A. M. P. de. Alfabetização científica: uma revisão bibliográfica. Investigações em ensino de ciências, Porto Alegre, v. 16, n. 1, p. 59-77, mar. 2011. Disponível em: https://www.if.ufrgs.br/cref/ojs/index.php/ienci/article/view/246/172. Acesso em: 06 abr. 2020. 